\title{
Bioavailability study of dronabinol oral solution versus dronabinol capsules in healthy volunteers
}

This article was published in the following Dove Press journal:

Clinical Pharmacology:Advances and Applications

12 October 2016

Number of times this article has been viewed

\author{
Neha Parikh' \\ William G Kramer ${ }^{2}$ \\ Varun Khurana' \\ Christina Cognata Smith' \\ Santosh Vetticaden' \\ 'INSYS Therapeutics, Inc., Chandler, \\ AZ, USA; ${ }^{2}$ Kramer Consulting LLC, \\ North Potomac, MD, USA
}

Background: Dronabinol, a pharmaceutical $\Delta$-9-tetrahydrocannabinol, was originally developed as an oral capsule. This study evaluated the bioavailability of a new formulation, dronabinol oral solution, versus a dronabinol capsule formulation.

Methods: In an open-label, four-period, single-dose, crossover study, healthy volunteers were randomly assigned to one of two treatment sequences (T-R-T-R and R-T-R-T; $\mathrm{T}=$ dronabinol $4.25 \mathrm{mg}$ oral solution and $\mathrm{R}=$ dronabinol $5 \mathrm{mg}$ capsule) under fasted conditions, with a minimum 7-day washout period between doses. Analyses were performed on venous blood samples drawn 15 minutes to 48 hours postdose, and dronabinol concentrations were assayed by liquid chromatography-tandem mass spectrometry.

Results: Fifty-one of 52 individuals had pharmacokinetic data for analysis. The $90 \%$ confidence interval of the geometric mean ratio (oral solution/capsule) for dronabinol was within the $80 \%-125 \%$ bioequivalence range for area under the plasma concentration-time curve (AUC) from time zero to last measurable concentration $\left(\mathrm{AUC}_{0-t}\right)$ and $\mathrm{AUC}$ from time zero to infinity $\left(\mathrm{AUC}_{0-\infty}\right)$. Maximum plasma concentration was also bioequivalent for the two dronabinol formulations. Intraindividual variability in $\mathrm{AUC}_{0-\infty}$ was $>60 \%$ lower for dronabinol oral solution $4.25 \mathrm{mg}$ versus dronabinol capsule $5 \mathrm{mg}$. Plasma dronabinol concentrations were detected within 15 minutes postdose in $100 \%$ of patients when receiving oral solution and in $<25 \%$ of patients when receiving capsules.

Conclusion: Single-dose dronabinol oral solution $4.25 \mathrm{mg}$ was bioequivalent to dronabinol capsule $5 \mathrm{mg}$ under fasted conditions. Dronabinol oral solution formulation may provide an easy-to-swallow administration option with lower intraindividual variability as well as more rapid absorption versus dronabinol capsules.

Keywords: pharmacokinetics, $\Delta$-9-tetrahydrocannabinol, safety, variability

\section{Introduction}

Dronabinol, a pharmaceutical formulation of $\Delta$-9-tetrahydrocannabinol ( $\Delta$-THC), is orally active (ie, oral administration results in adequate bioavailability to produce physiologic effects) and, similar to other cannabinoids, has complex effects on the central nervous system. ${ }^{1,2}$ Dronabinol has demonstrated efficacy in the treatment of anorexia associated with weight loss in patients with AIDS $^{3,4}$ and nausea and vomiting associated with cancer chemotherapy in patients who have failed to respond adequately to conventional antiemetic treatments ${ }^{5-8}$ and has been approved by the US Food and Drug Administration (FDA) for these indications.

Dronabinol was originally developed as a soft gelatin capsule. In this capsule formulation, oral dronabinol is almost completely absorbed (90\%-95\%) after
Correspondence: Santosh Vetticaden Department of Clinical Development and Medical Affairs, INSYS Therapeutics, Inc., I333 S Spectrum Boulevard, Suite 100, Chandler, AZ 85286, USA

$\mathrm{Tel}+\mathrm{I} 6029102617$

Email svetticaden@insysrx.com 
single dosing. ${ }^{9}$ However, only $10 \%-20 \%$ of oral dronabinol reaches the systemic circulation due to first-pass hepatic metabolism and high lipid solubility. In multiple-dose pharmacokinetic studies using healthy adults, the mean (standard deviation [SD]) maximum plasma concentration $\left(C_{\max }\right)$ of oral dronabinol capsule $5 \mathrm{mg}$ twice daily was 3.0 (1.8) $\mathrm{ng} / \mathrm{mL}$, the median time to $C_{\max }\left(\mathrm{T}_{\max }\right)$ was 2.5 hours (range, 0.5-4.0 hours), and the mean (SD) area under the plasma concentration-time curve (AUC) from time zero to 12 hours $\left(\mathrm{AUC}_{0-12}\right)$ was $6.2(1.8) \mathrm{h} \times \mathrm{ng} / \mathrm{mL} .{ }^{9}$ However, high variability in the pharmacokinetic parameters of oral THC, including dronabinol capsules, has been demonstrated in studies of healthy adults. ${ }^{10-12}$ Dronabinol has been shown to undergo extensive first-pass hepatic metabolism yielding the major metabolite $11-\mathrm{OH}-\Delta 9-\mathrm{THC}$ that is pharmacologically active and has an AUC similar to that of the parent drug. ${ }^{9}$

The oral delivery of dronabinol via a capsule may be less than ideal, such as in those with nausea and vomiting associated with cancer chemotherapy or swallowing difficulties. Thus, an easy-to-swallow oral solution formulation of dronabinol has been developed to provide an alternative delivery method. This study was designed to evaluate the bioequivalence of dronabinol oral solution $4.25 \mathrm{mg}$ versus dronabinol capsule $5 \mathrm{mg}$.

\section{Methods}

\section{Participants}

Males and females aged 18-55 years were eligible for the study if they were in good health as assessed by medical history, physical examination, and clinical laboratory investigations; had a body weight $\geq 50 \mathrm{~kg}$ and a body mass index of $19.0-29.9 \mathrm{~kg} /$ $\mathrm{m}^{2}$; and females were neither pregnant nor lactating. Individuals were excluded if they had used any prescription medicines (other than hormonal contraceptives) within 14 days, any over-the-counter medication within 7 days, or any vitamins or herbal supplements within 3 days before the first dose of study medication. Other exclusion criteria included marijuana use in the previous 90 days; smoking or other tobacco use in the previous 6 months; a history of mental illness, alcohol abuse, or physical dependence on any opioid, barbiturate, amphetamine, cocaine, or benzodiazepine in the past 10 years; or a positive screening test result for drugs of abuse. The study was conducted in accordance with the International Conference on Harmonisation principles of Good Clinical Practice and the Declaration of Helsinki. The study received institutional review board approval (IntegReview IRB, Austin, TX), and all patients provided written informed consent.

\section{Study design and treatment}

This randomized, open-label, two-treatment, four-period, two-sequence, single-dose, crossover study was conducted between September 2012 and October 2012 (ClinicalTrials. gov identifier: NCT01448772). Participants were randomly assigned to one of two treatment sequences: sequence 1 (T-R-T-R) and sequence 2 (R-T-R-T), where $\mathrm{T}$ was the test product (single oral dose of dronabinol oral solution $4.25 \mathrm{mg}$, lot number 100310 [Syndros ${ }^{\mathrm{TM}}$; INSYS Therapeutics, Inc., Phoenix, AZ, USA) and R was the reference product (single oral dose of dronabinol capsule $5 \mathrm{mg}$, lot number 277967A $\left[\mathrm{Marinol}^{\circledR}\right]$; expiration date December 2013; AbbVie, Inc., North Chicago, IL, USA). Each dose was administered under fasted conditions (overnight; $\geq 10$ hours) with $240 \mathrm{~mL}$ of water. Additional water was permitted as needed during the study except 1 hour predose through 1 hour postdose. Standardized meals were allowed starting 4 hours postdose. Each dose of study medication (test or reference product) was separated by a minimum 7-day washout period.

\section{Assessments}

Blood samples were collected by venipuncture before (predose) and at 0.25 hour, 0.5 hour, 0.75 hour, 1 hour, 1.5 hours, 2 hours, 2.5 hours, 3 hours, 3.5 hours, 4 hours, 6 hours, 8 hours, 12 hours, 16 hours, 24 hours, 36 hours, and 48 hours postdose. The plasma was harvested and frozen at $-20^{\circ} \mathrm{C}$ until analysis. Plasma concentrations of dronabinol and the primary metabolite 11-OH- $\triangle 9$-THC were analyzed by Worldwide Clinical Trials Drug Development Solutions (Austin, TX, USA) using a validated liquid chromatography-tandem mass spectrometry method, with a range of $0.025-10.0 \mathrm{ng} / \mathrm{mL}$ for each analyte, based on the analysis of $0.500 \mathrm{~mL}$ of plasma. Adverse events (AEs) were monitored throughout the study.

\section{Statistical analysis}

The safety population included all patients who received $\geq 1$ dose of study medication. The pharmacokinetic analysis population included all patients who completed the first two periods (T-R or R-T) within the sequence in which they were randomized. All statistical analyses were performed using SAS $^{\circledR}$ (version 9.3; SAS Institute Inc., Cary, NC, USA).

Pharmacokinetic parameters for dronabinol and 11-OH- $\Delta$ 9-THC were determined using standard noncompartmental methods. The $C_{\max }$ and $\mathrm{T}_{\max }$ were determined using observed data. The terminal elimination rate constant, $\lambda z$, was calculated as the negative of the slope of the terminal log-linear segment of the plasma concentration-time curve. Elimination half-life $\left(t_{1 / 2}\right)$ was calculated according to the 
following equation: $t_{1 / 2}=0.693 / \lambda z$. AUC from time zero to the final sample with a concentration greater than or equal to the lower limits of quantitation $\left(\mathrm{AUC}_{0-\mathrm{t}}\right)$ was calculated using the linear trapezoidal method and extrapolated to infinity using the equation

$$
\mathrm{AUC}_{0-\infty}=\mathrm{AUC}_{0-\mathrm{t}}+C_{\mathrm{tt}} / \lambda \mathrm{z}
$$

in which $C_{\mathrm{tf}}$ was the final concentration that is greater than or equal to the lower limits of quantitation.

A linear mixed-effects model was used to compare dronabinol oral solution and dronabinol capsule formulations using natural log-transformed pharmacokinetic parameters $\left(C_{\max }, \mathrm{AUC}_{0-\mathrm{t}}\right.$, and $\left.\mathrm{AUC}_{0-\infty}\right)$, uncorrected for dose, with sequence, treatment, period, and group as fixed effects and subject as a random effect. Geometric mean (GM) ratios (solution/capsule) were calculated for $C_{\max }, \mathrm{AUC}_{0-\mathrm{t}}$, and $\mathrm{AUC}_{0-\infty}$, and corresponding $90 \%$ confidence intervals (CIs) were determined using the two one-sided $t$-tests procedure ${ }^{13}$ on log-transformed data. The point estimates and confidence limits were back-transformed to the original scale. The two treatments were considered bioequivalent if the $90 \%$ CIs for $C_{\max }, \mathrm{AUC}_{0-\mathrm{t}}$, and $\mathrm{AUC}_{0-\infty}$ were within the range of $80 \%-125 \%$. For products demonstrating high intraindividual variability, the bioequivalence acceptance limit is sometimes adjusted based on the intraindividual variability of the capsule (reference) formulation. ${ }^{14-16}$ In accordance with the FDArecommended algorithm, if the intraindividual SDs (IISDs) for $C_{\max }$ and/or AUC of the reference product, as observed in the bioequivalence study, is or exceeds the cutoff value of 0.294 , then the bioequivalence limits for the test product are scaled based on the degree of variability of the reference product. ${ }^{16}$ A sample size of 60 individuals was determined to provide at least $80 \%$ power, $a=0.05$, to determine that the $90 \% \mathrm{CI}$ for the treatment comparison was between $80 \%$ and $125 \%$, assuming a difference in intraindividual coefficient between formulations of $\leq 5 \%$ for $C_{\max }$.

A post hoc analysis evaluated intraindividual variability on pharmacokinetic parameters and time to detectable plasma dronabinol level for the oral solution and capsule formulations. The intraindividual coefficient of variation (CV) was calculated for each pharmacokinetic parameter according to $100 \times(\mathrm{IISD} / \mathrm{LN}[\mathrm{GM}])$, where LN was the natural logarithmic function.

\section{Results}

A total of 52 patients were included in the safety population and 51 patients were included in the pharmacokinetic analysis population. Twenty-eight (53.9\%) of the 52 individuals were female, and $67.3 \%$ of individuals were white. The mean (SD) age was $33 \pm 10$ years (range, $18-53$ years) with a mean body mass index of $25.4 \pm 2.4 \mathrm{~kg} / \mathrm{m}^{2}$ (range, $21.0-29.9 \mathrm{~kg} / \mathrm{m}^{2}$ ). One participant withdrew prior to completion of the first two study periods and was excluded from the pharmacokinetic analysis population. Fifty of the 51 individuals in the pharmacokinetic analysis population completed all four periods (ie, received two doses each of test and reference products, with each dose separated by a 7-day washout period), and one participant withdrew after period 2 .

\section{Pharmacokinetic profile}

The mean plasma concentration-time curves of dronabinol and $11-\mathrm{OH}-\Delta 9-\mathrm{THC}$ are presented in Figure $1 \mathrm{~A}$ and $\mathrm{B}$, respectively. Pharmacokinetic parameters are summarized in Table 1. The median $\mathrm{T}_{\max }$ of dronabinol was shorter and the mean $\mathrm{t}_{1 / 2}$ was longer for dronabinol oral solution $4.25 \mathrm{mg}$ versus dronabinol capsule $5 \mathrm{mg}$. For the primary active metabolite 11-OH- $\Delta 9$-THC, the median $\mathrm{T}_{\max }$ and mean $\mathrm{t}_{1 / 2}$ were similar for the two dronabinol formulations.

For dronabinol, the $90 \% \mathrm{CIs}$ of the $\mathrm{GM}$ ratios for $\mathrm{AUC}_{0-\mathrm{t}}$ and $\mathrm{AUC}_{0-\infty}$ were within the bioequivalence range of $80 \%-125 \%$ (Table 2). The $90 \%$ CI for dronabinol $C_{\max }$ fell outside the bioequivalence range of $80 \%-125 \%$. Because the IISD for the $C_{\max }$ of the reference product (0.364) was $\geq 0.294$ (FDA criterion for a highly variable $\operatorname{drug}^{15,16}$ ) and the point estimate of the GM ratio of dronabinol $C_{\max }(82.50 \%)$ was within the bioequivalence range, the bioequivalence of $C_{\max }$ was evaluated using reference-scaled criteria. Using the reference-scaled approach, the point estimate of the GM ratio for dronabinol $C_{\max }(81.96 \%)$ was within the range of $80 \%$ $125 \%$, and the $95 \%$ upper confidence bound $(-0.01)$ was $\leq 0$, thereby meeting the FDA criteria for bioequivalence. ${ }^{15}$ For 11-OH- $\Delta 9$-THC (Table 2), the GM values for $C_{\max }, \mathrm{AUC}_{0-\mathrm{t}}$, and $\mathrm{AUC}_{0-\infty}$ were lower for dronabinol oral solution than for dronabinol capsule, and the lower limits of the $90 \%$ CIs of the GM ratios were $<80 \%$.

In a post hoc analysis of the intraindividual variability in dronabinol pharmacokinetic parameters (Table 3), the intraindividual $\mathrm{CV}$ for $\mathrm{AUC}_{0-\infty}$ was lower for dronabinol oral solution $4.25 \mathrm{mg}$ compared with dronabinol capsule $5 \mathrm{mg}$ (13.5\% versus $36.8 \%$, respectively). Regarding $C_{\max }$, intraindividual variability was greater for dronabinol oral solution versus dronabinol capsule $(\mathrm{CV}, 66.3 \%$ versus $53.8 \%$, respectively). A faster onset of detectable plasma concentrations was observed for dronabinol oral solution, with $100 \%$ of individuals with a detectable plasma dronabinol concentration at 15 minutes postdose when compared with $16.8 \%$ 

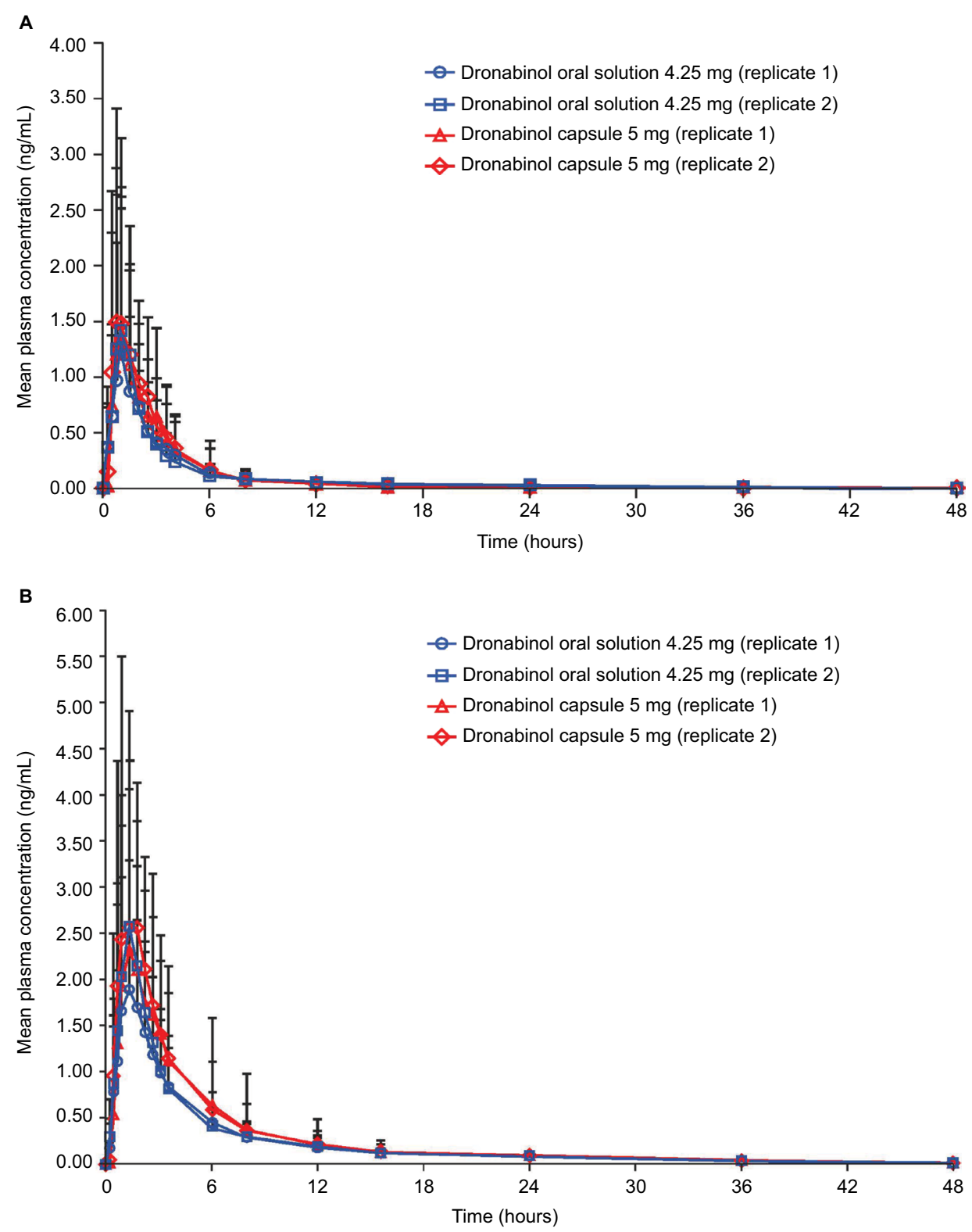

Figure I Linear mean plasma concentration-time curves for (A) dronabinol and (B) II-OH- $49-\mathrm{THC}$, after single-dose administration of dronabinol oral solution 4.25 mg or dronabinol capsule $5 \mathrm{mg}$, under fasted conditions.

Notes: $\mathrm{N}=5$ I for replicate I. $\mathrm{N}=50$ for replicate 2 .

Abbreviation: THC, tetrahydrocannabinol.

of individuals after administration of dronabinol capsule (Figure 2).

\section{Adverse events}

Single-dose administration of dronabinol oral solution $4.25 \mathrm{mg}$ and dronabinol capsule $5 \mathrm{mg}$ was generally well tolerated. A total of 90 AEs were reported by 25 individuals during the study, with $48.9 \%$ and $51.1 \%$ of AEs reported with dronabinol oral solution and dronabinol capsule, respectively. The most commonly reported AEs in the safety population were nausea $(n=14$; dronabinol oral solution, $n=8$, versus dronabinol capsule, $n=6$ ), dizziness $(n=13$; dronabinol oral solution, $\mathrm{n}=6$, versus dronabinol capsule, $\mathrm{n}=7$ ), somnolence $(\mathrm{n}=12$; dronabinol oral solution, $\mathrm{n}=7$, versus dronabinol capsule, $n=5)$, and headache ( $\mathrm{n}=11$; dronabinol oral solution, $\mathrm{n}=7$, versus dronabinol capsule, $\mathrm{n}=4)$. All AEs were considered mild $(50 \%)$ or moderate $(50 \%)$ in intensity.

\section{Discussion}

This comparative bioavailability study demonstrated the bioequivalence of single-dose dronabinol oral solution $4.25 \mathrm{mg}$ to dronabinol capsule $5 \mathrm{mg}$ in healthy volunteers, under fasted conditions. The $90 \%$ CI of the GM ratio (oral solution/capsule) was within the standard bioequivalence range 
Table I Pharmacokinetics of dronabinol and I I-OH- $\triangle 9-\mathrm{THC}$ after single-dose administration of dronabinol oral solution or dronabinol capsule

\begin{tabular}{|c|c|c|c|c|}
\hline \multirow[t]{2}{*}{ Parameter $^{\mathrm{a}}$} & \multicolumn{2}{|c|}{ Dronabinol oral solution $4.25 \mathrm{mg}$} & \multicolumn{2}{|c|}{ Dronabinol capsule 5 mg } \\
\hline & Replicate I, N=5 I & Replicate 2, N=50 & Replicate I, N=5 I & Replicate 2, N=50 \\
\hline \multicolumn{5}{|l|}{ Dronabinol } \\
\hline$C_{\max }(\mathrm{ng} / \mathrm{mL})$ & $1.81(1.26)$ & $2.08(1.30)$ & $2.20(1.5 \mathrm{I})$ & $2.61(1.69)$ \\
\hline $\mathrm{T}_{\max }$ (hours) & $1.50(0.50-4.00)$ & $1.00(0.50-3.02)$ & $1.00(0.50-6.00)$ & $1.50(0.50-6.00)$ \\
\hline$A \cup C_{0-t}(h \times n g / m L)$ & $3.44(1.98)$ & $3.62(1.75)$ & $3.75(2.36)$ & $4.23(2.65)$ \\
\hline$A \cup C_{0-\infty}(h \times n g / m L)$ & $3.75(2.04)^{\mathrm{b}}$ & $3.94(1.50)^{c}$ & $3.85(2.32)^{d}$ & $4.27(2.70)^{\mathrm{e}}$ \\
\hline$\lambda z(\mathrm{I} / \mathrm{h})$ & $0.16(0.07)^{\mathrm{b}}$ & $0.14(0.06)^{c}$ & $0.36(0.16)^{d}$ & $0.29(0.15)^{e}$ \\
\hline $\mathrm{t}_{1 / 2}$ (hours) & $5.41(3.06)^{b}$ & $5.78(2.13)^{c}$ & $2.68(2.39)^{d}$ & $3.52(2.87)^{\mathrm{e}}$ \\
\hline \multicolumn{5}{|l|}{ II-ОH- $\Delta 9-$-THC } \\
\hline$C_{\max }(\mathrm{ng} / \mathrm{mL})$ & $2.53(1.38)$ & $3.01(1.56)$ & $3.28(1.78)$ & $3.98(2.5 \mathrm{I})$ \\
\hline $\mathrm{T}_{\max }$ (hours) & $1.50(0.75-4.00)$ & $1.50(0.50-3.02)$ & $1.60(0.75-6.00)$ & $1.50(0.50-6.00)$ \\
\hline$A \cup C_{0-t}(h \times n g / m L)$ & $10.1(5.2 I)$ & II.I (5.05) & $12.2(6.20)$ & $13.5(7.12)$ \\
\hline $\mathrm{AUC}_{0-\infty}(\mathrm{h} \times \mathrm{ng} / \mathrm{mL})$ & $10.7(5.5)^{f}$ & II.8 (5.19)g & $\mid 3.3(6.4 \mid)^{\mathrm{h}}$ & $14.3(7.34)^{b}$ \\
\hline$\lambda z(\mathrm{I} / \mathrm{h})$ & $0.07(0.05)^{f}$ & $0.07(0.04)^{g}$ & $0.08(0.08)^{\mathrm{h}}$ & $0.07(0.03)^{\mathrm{b}}$ \\
\hline $\mathrm{t}_{1 / 2}$ (hours) & II $.6(4.39)^{f}$ & $11.7(3.61)^{g}$ & II.8 $(4.17)^{\mathrm{h}}$ & $11.9(3.6)^{b}$ \\
\hline
\end{tabular}

Notes: $\lambda z$, terminal elimination rate constant; $A U C_{0-t}, A U C$ from time zero to last measurable concentration; $A U C_{0-\infty}, A U C$ from time zero to infinity; $C_{\text {max }}$, maximum plasma concentration; $t_{1 / 2}$, elimination half-life; $T_{\max }$, the median time to $C_{\max }{ }^{a} D a t a$ are mean (SD) except $T_{\max }$, which is median (range): ${ }^{b} n=49$. ${ }^{c} n=42$. ${ }^{d} n=46$. ${ }^{e} n=40$. ${ }^{f} n=50$. ${ }^{g} n=47 .{ }^{h} n=48$.

Abbreviations: AUC, area under the plasma concentration-time curve; SD, standard deviation; THC, tetrahydrocannabinol.

Table 2 Determination of bioequivalence of single-dose dronabinol oral solution versus dronabinol capsule

\begin{tabular}{|c|c|c|c|c|c|}
\hline \multirow[t]{2}{*}{ Parameter } & \multirow{2}{*}{$\begin{array}{l}\text { Dronabinol oral } \\
\text { solution } 4.25 \mathrm{mg} \text {, } \\
\text { geometric LSM }\end{array}$} & \multirow{2}{*}{$\begin{array}{l}\text { Dronabinol capsule } \\
5 \mathrm{mg} \text {, geometric LSM }\end{array}$} & \multirow{2}{*}{$\begin{array}{l}\text { Geometric mean } \\
\text { ratio }(90 \% \mathrm{Cl})^{\mathrm{a}}\end{array}$} & \multicolumn{2}{|l|}{ Intraindividual SD } \\
\hline & & & & $\begin{array}{l}\text { Dronabinol oral } \\
\text { solution } 4.25 \mathrm{mg}\end{array}$ & $\begin{array}{l}\text { Dronabinol capsule } \\
5 \mathrm{mg}\end{array}$ \\
\hline \multicolumn{6}{|l|}{ Dronabinol } \\
\hline$C_{\max }$ & 1.62 & 1.97 & $82.50^{\mathrm{b}}(74.62-91.22)$ & 0.32 & 0.36 \\
\hline $\mathrm{AUC}_{0-\mathrm{t}}$ & 3.12 & 3.32 & $94.07(84.59-104.61)$ & 0.19 & 0.43 \\
\hline$A \cup C_{0-\infty}^{0-\tau}$ & 3.45 & 3.43 & $100.39(89.47-|| \mid 2.65)$ & 0.17 & 0.45 \\
\hline \multicolumn{6}{|c|}{ I I-OH- $\Delta 9-$ THC } \\
\hline$C_{\max }$ & 2.36 & 3.05 & 77.33 (72.50-82.49) & 0.29 & 0.26 \\
\hline$A \cup C_{0-t}$ & 9.05 & 10.90 & $82.97(77.98-88.28)$ & 0.21 & 0.22 \\
\hline $\mathrm{AUC}_{0-\infty}$ & 9.67 & 11.53 & $83.92(79.02-89.11)$ & 0.19 & 0.22 \\
\hline
\end{tabular}

Notes: $A_{U C}, A \cup C$ from time zero to infinity; $A \cup C_{0-t}, A \cup C$ from time zero to last measurable concentration; $C_{\text {max }}$, maximum plasma concentration. Results were calculated for all participants who completed $\geq 2$ study periods $(\mathrm{N}=5 \mathrm{I})$. ${ }^{\text {aB }}$ ased on analysis of natural log-transformed data. ${ }^{\mathrm{b}} \mathrm{Using}$ the reference-scaled approach, the point estimate of the geometric mean ratio was 81.96 , and the $95 \%$ upper confidence bound was -0.01 , which met the criteria for bioequivalence.

Abbreviations: AUC, area under the plasma concentration-time curve; $\mathrm{Cl}$, confidence interval; LSM, least-squares mean; SD, standard deviation; THC, tetrahydrocannabinol.

Table 3 Intraindividual variability of dronabinol pharmacokinetic parameters after single-dose administration of dronabinol oral solution or dronabinol capsule

\begin{tabular}{|c|c|c|c|c|c|c|}
\hline \multirow[t]{2}{*}{ Parameter } & \multicolumn{2}{|l|}{ GM } & \multicolumn{2}{|l|}{ IISD } & \multicolumn{2}{|c|}{ Intraindividual CV (\%) } \\
\hline & $\begin{array}{l}\text { Dronabinol oral } \\
\text { solution } 4.25 \mathrm{mg}\end{array}$ & $\begin{array}{l}\text { Dronabinol } \\
\text { capsule } 5 \mathrm{mg}\end{array}$ & $\begin{array}{l}\text { Dronabinol oral } \\
\text { solution } 4.25 \mathrm{mg}\end{array}$ & $\begin{array}{l}\text { Dronabinol } \\
\text { capsule } 5 \mathrm{mg}\end{array}$ & $\begin{array}{l}\text { Dronabinol oral } \\
\text { solution } 4.25 \mathrm{mg}\end{array}$ & $\begin{array}{l}\text { Dronabinol } \\
\text { capsule } 5 \mathrm{mg}\end{array}$ \\
\hline$\overline{C_{\max }}$ & 1.62 & 1.97 & 0.321 & 0.364 & 66.3 & 53.8 \\
\hline$A \cup C_{0-\infty}$ & 3.45 & 3.43 & 0.167 & 0.453 & 13.5 & 36.8 \\
\hline
\end{tabular}

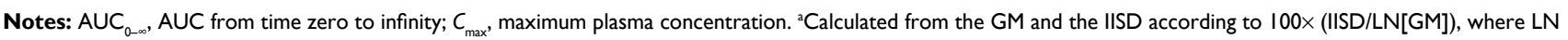
is the natural logarithmic function.

Abbreviations: AUC, area under the plasma concentration-time curve; CV, coefficient of variation; GM, geometric mean; IISD, intraindividual standard deviation.

of $80 \%-125 \%$ for $\mathrm{AUC}_{0-\mathrm{t}}$ and $\mathrm{AUC}_{0-\infty} . C_{\max }$ was comparable for the oral solution and capsule formulations based on FDA-recommended reference-scaled criteria. Intraindividual variability in total exposure $\left(\mathrm{AUC}_{0-\infty}\right)$ was $>60 \%$ lower for the oral solution compared with capsules. In addition, faster absorption was observed for the oral solution formulation.
The bioequivalence of dronabinol oral solution with dronabinol capsules was established using FDA-recommended study design and methodology. ${ }^{17,18}$ For reference drugs identified as highly variable (ie, IISD $\geq 0.29$ in a bioequivalence study), a reference-scaled approach is recommended. ${ }^{15,16}$ The IISD for dronabinol capsule $5 \mathrm{mg}$ in 


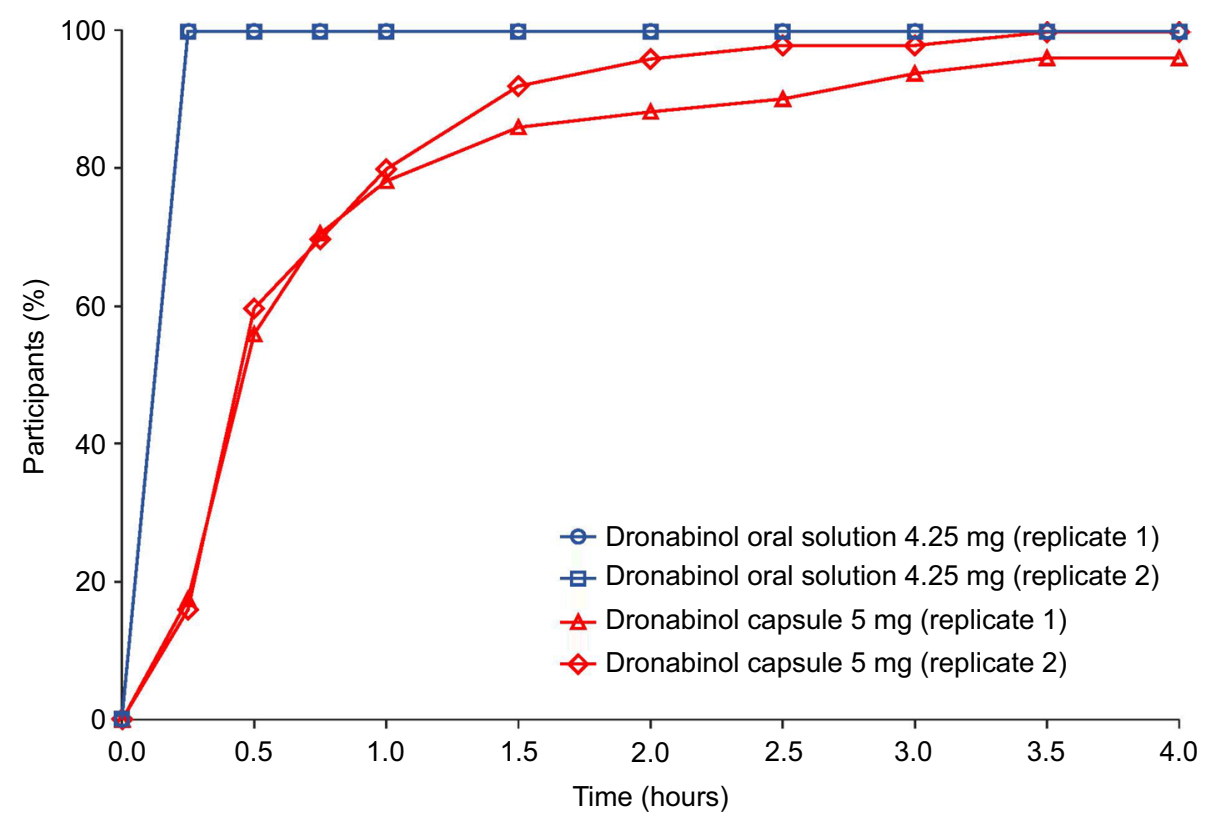

Figure 2 Percentage of participants with measurable plasma dronabinol concentration $(\geq 0.025 \mathrm{ng} / \mathrm{mL})$ after single-dose administration of dronabinol oral solution $4.25 \mathrm{mg}$ or dronabinol capsule $5 \mathrm{mg}$, under fasted conditions.

Notes: $\mathrm{N}=5 \mathrm{I}$ for replicate I. $\mathrm{N}=50$ for replicate 2 .

the current study was $>0.29$ for dronabinol $C_{\max }, \mathrm{AUC}_{0-\mathrm{t}}$, and $\mathrm{AUC}_{0-\infty}$. Despite this variability, the $90 \% \mathrm{CIs}$ for the $\mathrm{GM}$ ratios (oral solution/capsule) of dronabinol $\mathrm{AUC}_{0-\mathrm{t}}$ and $\mathrm{AUC}_{0-\infty}$ were within the bioequivalence range (80\%-125\%). The point estimate for the $\mathrm{C}_{\max } \mathrm{GM}$ ratio (82.5\%) was within the bioequivalence range, but the lower limit of the $90 \% \mathrm{CI}$ $(74.6 \%)$ fell outside the range. Therefore, dronabinol $C_{\max }$ for the oral solution was evaluated using a reference-scaled approach and met the FDA-recommended criteria for bioequivalence. ${ }^{15}$ For the primary active metabolite of dronabinol (11-OH- $\Delta 9-\mathrm{THC}$ ), the mean plasma concentrations were slightly lower after administration of oral solution when compared with capsule and were considered indicative of the similarity between the oral solution and capsule products.

This post hoc analysis demonstrated important attributes for dronabinol oral solution relative to dronabinol capsules, with lower intraindividual $\mathrm{CV}$ for $\mathrm{AUC}_{0-\infty}(13.5 \%$ versus $36.8 \%$, respectively) and faster onset of detectable plasma concentrations in $100 \%$ and $16.8 \%$ of individuals, respectively, at 15 minutes postdose. Variability for $C_{\max }$ was greater for dronabinol oral solution versus dronabinol capsule $(66.3 \%$ versus $53.8 \%$, respectively). The frequency of AEs was comparable between dronabinol oral solution and dronabinol capsule. Limitations of the study include that the study population was composed of only healthy adults; the pharmacokinetics of dronabinol may differ in patients with cancer or AIDS and in the presence of antineoplastic agents or other concomitant medications. In addition, this was a single-dose study and does not reflect the steady-state pharmacokinetics of dronabinol.
Furthermore, because this study was conducted in healthy adults, additional studies may be needed to assess the clinical relevance of faster onset of detectable plasma concentrations and lower intraindividual variability in a patient population.

The efficacy of dronabinol ( $\Delta 9-\mathrm{THC})$ as an antiemetic for patients with chemotherapy-induced nausea and vomiting and as an appetite stimulant for patients with AIDS is supported by multiple studies of capsule formulations..$^{3-5,7,8,19-24}$ Potential limitations of prior dronabinol formulations have included variable bioavailability and delayed absorption, which are important considerations that limit the optimal treatment of patients. ${ }^{25}$ Specifically, it has been noted with prior formulations, as stated by Lucas and $\mathrm{Laszlo}^{7}$ in 1980 , that " $\Delta$ 9-tetrahydrocannabinol is erratically absorbed from the gastrointestinal tract, and dosage individualization may be necessary to control these patients." Consequently, intraindividual and interindividual variabilities are likely to have important implications for safety and efficacy with dronabinol products, as well as patient adherence. In this regard, the $>60 \%$ lower intraindividual variability in absorption with the oral solution compared with the capsule formulation is noteworthy. Another important finding of this study was that detectable concentrations of dronabinol oral solution were observed in a substantially greater percentage of patients within 15 minutes postdose with dronabinol oral solution versus dronabinol capsule. The faster onset of detectable concentrations observed with dronabinol oral solution may be an additional consideration for physicians in selecting the appropriate dronabinol formulation for their patients. Furthermore, the oral solution may offer flexibility in dosing calculations in 
cancer settings (eg, as an antiemetic for patients undergoing chemotherapy, for which the recommended dronabinol dose is based on body surface $\operatorname{area}^{9}$ ).

\section{Conclusion}

This pharmacokinetic study demonstrated the bioequivalence of dronabinol oral solution $4.25 \mathrm{mg}$ and dronabinol capsule $5 \mathrm{mg}$ under fasted conditions in healthy volunteers. The attributes of the dronabinol oral solution formulation, including lower intraindividual variability and faster onset of detectable concentrations relative to dronabinol capsule, may be important considerations in the selection of the optimal formulation of dronabinol for the treatment of patients.

\section{Acknowledgments}

Technical editorial and medical writing assistance for the development of this article was provided by Mary Beth Moncrief, $\mathrm{PhD}$, and Nancy Holland, $\mathrm{PhD}$, Synchrony Medical Communications, LLC, West Chester, PA, USA. Funding for this support was provided by INSYS Therapeutics, Inc., which had a role in study design, supervision of data collection, analysis and interpretation of data, and reporting of results. Some of the content herein was published in a "Meeting Abstracts" supplement issue from The American Society of Clinical Oncology annual meeting: Journal of Clinical Oncology. 2016;34(15 suppl):e21593: http://meeting.ascopubs.org/ cgi/content/abstract/34/15 suppl/e21593. The abstract was not presented at the meeting.

\section{Disclosure}

NP, VK, CCS, and SV are full-time employees of INSYS Therapeutics, Inc. WGK is a paid consultant to INSYS Therapeutics, Inc. The authors report no other conflicts of interest in this work.

\section{References}

1. Pertwee RG. Pharmacological actions of cannabinoids. Handb Exp Pharmacol. 2005;168:1-51.

2. Grotenhermen F. Pharmacokinetics and pharmacodynamics of cannabinoids. Clin Pharmacokinet. 2003;42(4):327-360.

3. Beal JE, Olson R, Lefkowitz L, et al. Long-term efficacy and safety of dronabinol for acquired immunodeficiency syndrome-associated anorexia. J Pain Symptom Manage. 1997;14(1):7-14.

4. Beal JE, Olson R, Laubenstein L, et al. Dronabinol as a treatment for anorexia associated with weight loss in patients with AIDS. J Pain Symptom Manage. 1995;10(2):89-97.

5. Lane M, Vogel CL, Ferguson J, et al. Dronabinol and prochlorperazine in combination for treatment of cancer chemotherapy-induced nausea and vomiting. J Pain Symptom Manage. 1991;6(6):352-359.

6. Plasse TF, Gorter RW, Krasnow SH, Lane M, Shepard KV, Wadleigh RG. Recent clinical experience with dronabinol. Pharmacol Biochem Behav. 1991;40(3):695-700.
7. Lucas VS Jr, Laszlo J. Delta 9-tetrahydrocannabinol for refractory vomiting induced by cancer chemotherapy. JAMA. 1980;243(12):1241-1243.

8. Orr LE, McKernan JF, Bloome B. Antiemetic effect of tetrahydrocannabinol. Compared with placebo and prochlorperazine in chemotherapy-associated nausea and emesis. Arch Intern Med. 1980;140(11):1431-1433.

9. Marinol $^{\circledR}$ (dronabinol) capsules [package insert]. North Chicago, IL: AbbVie, Inc.; 2015.

10. Wall ME, Perez-Reyes M. The metabolism of delta 9-tetrahydrocannabinol and related cannabinoids in man. JClin Pharmacol. 1981;21(8-9 suppl): 178S-189S.

11. Naef M, Curatolo M, Petersen-Felix S, Arendt-Nielsen L, Zbinden A, Brenneisen R. The analgesic effect of oral delta-9-tetrahydrocannabinol (THC), morphine, and a THC-morphine combination in healthy subjects under experimental pain conditions. Pain. 2003;105(1-2):79-88.

12. Ahmed AI, van den Elsen GA, Colbers A, et al. Safety and pharmacokinetics of oral delta-9-tetrahydrocannabinol in healthy older subjects: a randomized controlled trial. Eur Neuropsychopharmacol. 2014;24(9):1475-1482.

13. Schuirmann DJ. A comparison of the two one-sided tests procedure and the power approach for assessing the equivalence of average bioavailability. J Pharmacokinet Biopharm. 1987;15(6):657-680.

14. Haidar SH, Davit B, Chen ML, et al. Bioequivalence approaches for highly variable drugs and drug products. Pharm Res. 2008;25(1):237-241.

15. US Department of Health and Human Services, US Food and Drug Administration, Center for Drug Evaluation and Research [webpage on the Internet]. Draft Guidance on Progesterone. 2011. Available from: http://www.fda.gov/downloads/Drugs/GuidanceComplianceRegulato ryInformation/Guidances/UCM209294.pdf. Accessed March 15, 2016.

16. Davit BM, Chen ML, Conner DP, et al. Implementation of a referencescaled average bioequivalence approach for highly variable generic drug products by the US Food and Drug Administration. AAPS J. 2012; 14(4):915-924.

17. US Department of Health and Human Services, US Food and Drug Administration, Center for Drug Evaluation and Research [webpage on the Internet]. Draft Guidance on Dronabinol. 2014. Available from: http://www.fda.gov/downloads/drugs/guidancecomplianceregulatoryin formation/guidances/ucm199636.pdf. Accessed March 15, 2016.

18. US Department of Health and Human Services, US Food and Drug Administration, Center for Drug Evaluation and Research (CDER) [webpage on the Internet]. Guidance for Industry Bioavailability and Bioequivalance Studies Submitted in NDAs or INDs - General Considerations. 2014. Available from: http://www.fda.gov/downloads/drugs/ guidancecomplianceregulatoryinformation/guidances/ucm389370.pdf. Accessed March 15, 2016.

19. Ungerleider JT, Andrysiak T, Fairbanks L, Goodnight J, Sarna G, Jamison K. Cannabis and cancer chemotherapy: a comparison of oral delta-9-THC and prochlorperazine. Cancer. 1982;50(4):636-645.

20. Ekert H, Waters KD, Jurk IH, Mobilia J, Loughnan P. Amelioration of cancer chemotherapy-induced nausea and vomiting by delta-9-tetrahydrocannabinol. Med J Aust. 1979;2(12):657-659.

21. Frytak S, Moertel CG, O'Fallon JR, et al. Delta-9-tetrahydrocannabinol as an antiemetic for patients receiving cancer chemotherapy. A comparison with prochlorperazine and a placebo. Ann Intern Med. 1979;91(6): $825-830$.

22. Kluin-Neleman JC, Neleman FA, Meuwissen OJ, Maes RA. delta 9-tetrahydrocannabinol (THC) as an antiemetic in patients treated with cancerchemotherapy; a double-blind cross-over trial against placebo. Vet Hum Toxicol. 1979;21(5):338-340.

23. Sallan SE, Cronin C, Zelen M, Zinberg NE. Antiemetics in patients receiving chemotherapy for cancer: a randomized comparison of delta-9-tetrahydrocannabinol and prochlorperazine. NEngl JMed. 1980;302(3):135-138.

24. Sallan SE, Zinberg NE, Frei EI. Antiemetic effect of delta-9-tetrahydrocannabinol in patients receiving cancer chemotherapy. $N$ Engl J Med. 1975;293(16):795-797.

25. Chang AE, Shiling DJ, Stillman RC, et al. Delta-9-tetrahydrocannabinol as an antiemetic in cancer patients receiving high-dose methotrexate: a prospective, randomized evaluation. Ann Intern Med. 1979;91(6):819-824. 
Clinical Pharmacology: Advances and Applications is an international, peer-reviewed, open access journal publishing original research, reports, reviews and commentaries on all areas of drug experience in humans. The manuscript management system is completely online and includes a very quick and fair peer-review system, which is all easy to use.

Submit your manuscript here: https://www.dovepress.com/clinical-pharmacology-advances-and-applications-journal
Visit http://www.dovepress.com/testimonials.php to read real quotes from published authors. 